\title{
Modelling Acidic Solute Fluxes to the Water Column in the Lower Lakes
}

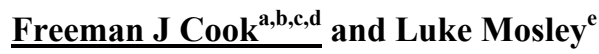 \\ ${ }^{a}$ Freeman Cook and Associates PTY LTD, ${ }^{c}$ The University of Queensland School of Agriculture and Food \\ Sciences, St Lucia, Queensland, Australia, ${ }^{c}$ CSIRO Land and Water, Dutton Park, Queensland, Australia, ${ }^{d}$ \\ Griffith University, Atmospheric Environment Research Centre, Nathan, Q4111, Australia, ${ }^{e}$ South Australian \\ Environmental Protection Agency \\ Email:freeman.j.cook@gmail.com
}

\begin{abstract}
During the recent drought in the Murray-Darling Basin in flow to the lower lakes was severely restricted, which led to a reduction in the lake levels to as low as -1.0 m AHD. This resulted in exposure of sediments with pyritic minerals and the subsequent oxidation of these to produce acidic sediments. Upon refilling of the lower lakes these sediments were inundated, providing a pathway for this acidity to be transport to the lake water. The rate of acidity $\left(\mathrm{H}^{+}, \mathrm{Fe}^{2+}, \mathrm{Al}^{3+}\right)$ transport to the lake water, the time course of acidity transport and the possible effects on the lake water alkalinity are not known. In order to provide some guidance on these issues, models to estimate the flux of this acidity to the lake water were developed.
\end{abstract}

These models were based on the analytical solutions for solute transport in porous media collated by van Genuchten and Alves (1982). The solution we used is a pulse input with a concentration of $c_{0}$, constant initial concentrations; $c_{1}$, in the sediment to a depth of $z_{1}$ and $c_{2}$ for $z_{1}<z \leq \infty$, which results in the concentration being given by:

$c(z, t)=c_{2}+\left(c_{1}-c_{2}\right) A(z, t)+B\left(c_{0}-c_{1}\right), A(z, t)=\frac{1}{2} \operatorname{erfc}\left[\frac{R\left(z-z_{1}\right)}{2 \sqrt{R D t}}\right]+\frac{1}{2} \exp \left(\frac{q z}{D}\right) \operatorname{erfc}\left[\frac{R\left(z+z_{1}\right)}{2 \sqrt{R D t}}\right], B(z, t)=\frac{1}{2} \operatorname{erfc}\left[\frac{R z-q t}{2 \sqrt{R D t}}\right]+\frac{1}{2} \exp \left(\frac{q z}{D}\right) \operatorname{erfc}\left[\frac{R z+q t}{2 \sqrt{R D t}}\right]^{(1)}$

where $R$ is the retardation, $z$ is depth $(\mathrm{m}), t$ is time $(\mathrm{s}), q$ is Darcy flux $\left(\mathrm{m} \mathrm{s}^{-1}\right)$ and $D$ is the dispersivity $\left(\mathrm{m}^{2} \mathrm{~s}^{-}\right.$ $\left.{ }^{1}\right)$. The solutes modelled were, $\mathrm{H}^{+}, \mathrm{Fe}^{2+}$, and $\mathrm{Al}^{3+}$ and total acidity, taken as $\mathrm{H}^{+}$equivalent of the metals.

Table 1. Modelled and measured flux rates $\left(\mathrm{mol} \mathrm{H}^{+} \mathrm{m}^{-2}\right.$ day $\left.{ }^{-1}\right)$ from Hicks et al. (2009, Table 8). Negative values indicate flux from the sediment to the water column and positive values from the water column to the sediment. Advection results are for $q>0$.

\begin{tabular}{|c|c|c|c|c|c|c|}
\hline \multirow{2}{*}{$\begin{array}{l}\text { Location } \\
\text { Boggy Creek }\end{array}$} & \multicolumn{2}{|c|}{$\begin{array}{c}\text { Measured } \\
\left(\mathrm{mol} \mathrm{H}^{+} \mathrm{m}^{-2} \text { day }^{-1}\right)\end{array}$} & \multicolumn{2}{|c|}{$\begin{array}{c}\text { Modelled }\left(\mathrm{mol} \mathrm{H}^{+} \mathrm{m}^{-2} \text { day }^{-1}\right) \\
\text { Diffusion only }\end{array}$} & \multicolumn{2}{|c|}{$\begin{array}{c}\text { Modelled }\left(\mathrm{mol} \mathrm{H}^{+} \mathrm{m}^{-2} \text { day }^{-1}\right) \\
\text { Diffusion }+ \text { Advection }\end{array}$} \\
\hline & Day 1 & Day $7-102$ & Day 1 & Day $7-102$ & Day 1 & Day $7-102$ \\
\hline Fresh water & $-1.6 \times 10^{-1}$ & $-6.0 \times 10^{-3}$ & $-3.3 \times 10^{-1}$ & $-23 \times 10^{-3}$ & $-3.4 \times 10^{-1}$ & $-9 \times 10^{-3}$ \\
\hline Sea water & $-5.3 \times 10^{-1}$ & $-22 \times 10^{-3}$ & $-9.1 \times 10^{-1}$ & $-73 \times 10^{-3}$ & $-8.4 \times 10^{-1}$ & $-20 \times 10^{-3}$ \\
\hline Point Sturt & Day 1 & Day $12-100$ & Day 1 & Day $12-100$ & Day 1 & Day $12-100$ \\
\hline Fresh water & $-1.38 \times 10^{-1}$ & $5 \times 10^{-3}$ & $-0.65 \times 10^{-1}$ & $-3 \times 10^{-3}$ & $-0.52 \times 10^{-1}$ & $-1.5 \times 10^{-4}$ \\
\hline Sea water & $-2.8 \times 10^{-1}$ & $7 \times 10^{-3}$ & $-196 \times 10^{-1}$ & $-4 \times 10^{-3}$ & $-60 \times 10^{-1}$ & $-1 \times 10^{-4}$ \\
\hline
\end{tabular}

The modelled fluxes for the mesocosms of Hicks et al. (2009) were compared to measurements conducted in these mesocosm experiments conducted by and found to give similar results (Table 1). The advective velocities were estimated from measurements by Hicks et al. (2009) of the infiltration of water into the sediments.

These results indicate that fluxes modelled using eqn (1) are similar to those measured. The modelling was performed using molecular diffusion for dispersivity of the solutes. The reason that such good results were obtained with just molecular diffusion is that the drying out of the lakes and acidity had killed almost all the benthic organisms (Baring et al. 2008). These results indicated that for Lake Alexandrina, the alkalinity of this lake could easily cope with this acid flux but for Lake Albert, the acid flux would be close to the alkalinity supply of the lake waters.

Keywords: $\quad$ Sediment solute fluxes, Lower Lakes, modelling, water quality 


\section{INTRODUCTION}

The drought in the Murray Darling Basin in the recent years led to a reduction in the water level in the lower lakes (Lake Alexandrian and Lake Albert, shown in figure 1), to as low as $-1.0 \mathrm{~m}$ AHD. This resulted in the formation of acidic sediments due to oxidation of sulfides in the sediments (Fitzpatrick et al., 2008) and surface and groundwater turning acidic on the lake margins (Mosley et al., 2013). In 2009, the lakes started to refill, covering the sediments and beginning the process of recovery in terms of the water levels, water quality and ecosystems. However, it is difficult to know the length of this recovery, given acidity is still present in the sediments. In particular, the potential for toxic effects on the benthic community, a major component of the ecosystem is currently unknown. The rate of the acidity flux from the sediments to the water column as a function of time and the effect of this on the alkalinity of the lake water is likely to have an effect on the recovery of the ecosystem in the lower lakes.

Numerous models have been developed to predict the transport of solutes to and from sediments. These vary from the simple box models (Marion et al. 2003) to full description of all processes (Meysman et al. 2007):

$$
\rho\left[\frac{1}{\phi} \frac{\partial q}{\partial t}+\frac{1}{\phi}(q \cdot \nabla) q\right]=-\nabla p+\rho g \nabla z+\tilde{\mu} \nabla^{2} q-\rho \frac{C_{f}}{\sqrt{k}}\|q\| q
$$

where $k$ is the permeability, $\mu$ is the dynamic viscosity, $\tilde{\mu}$ is the effective viscosity $\rho$ is the pore water density, $C_{f}$ a dimensional drag coefficient, $g$ gravity and $z$ the vertical coordinate. The Darcy velocity $q$ is related to the actual velocity of the pore water $(v)$ by $q=\phi v$ where $\phi$ is the porosity. The non-linear drag (Forchheimer) is negligibly small, particularly in sands, and can be ignored. The Brinkman term is only important in the interface between the benthos and the water where the velocity term shows strong curvature $\left(\nabla^{2} q\right.$ large ). This region of importance is of the order of the grain diameter, so in sands is approximately 2 $\mathrm{mm}$, and again in most circumstances can be ignored. This then leaves the Darcy equation for flow:

$$
q=-\frac{k}{\mu}(\nabla p-\rho g \nabla z)
$$

When combined with the continuity equation, this gives (Meysman et al. 2007):

$$
\frac{\partial C}{\partial t}=\nabla \cdot(D \cdot \nabla \cdot C+q C)+R_{r}
$$

where $C$ is the solute concentration, $D$ is the dispersion tensor and $R_{r}$ is an overall production rate for the chemical species. This is the same as equations for solute transport in soil. van Genuchten and Alves (1982) collated analytical solutions of solute transport described by eqn (3) for various initial and boundary conditions. A solution for a pulse input with a concentration of $c_{0}$, constant initial concentrations; $c_{1}$, in the sediment to a depth of $z_{1}$ and $c_{2}$ for $z_{1}<z \leq \infty$, which results in the concentration being given eqn (1) above.

The dispersion in sediments is the result of a number of processes and the apparent dispersion,

Table 2. Molecular diffusion of ions in water and base and range of values used in sensitivity analysis.

\begin{tabular}{l|c|c|c}
\hline Ion & $D_{0}\left(\mathrm{~m}^{2}\right.$ day $\left.^{-1}\right)$ & Parameter & Base value (Range) \\
\hline $\mathrm{H}^{+}$ & $8.06 \times 10^{-4}$ & $c_{1}\left(\mathrm{~kg} \mathrm{~m}^{-3}\right)$ & $10(1$ to 100$) \times 10^{-3}$ \\
$\mathrm{Fe}^{2+}$ & $0.61 \times 10^{-4}$ & $D\left(\mathrm{~m}^{2} \mathrm{day}^{-1}\right)$ & $5(0.5$ to 25$) \times 10^{-4}$ \\
$\mathrm{Al}^{3+}$ & $0.47 \times 10^{-4}$ & $z_{1}(\mathrm{~m})$ & $0.5(0.1$ to 1.0$)$ \\
& & $q\left(\mathrm{~m} \mathrm{day}^{-1}\right)$ & $1(-1$ to 4$) \times 10^{-2}$ \\
\hline
\end{tabular}
$D_{m}\left(\mathrm{~m}^{2} \mathrm{~s}^{-1}\right)$ can be written as (van Rees et al. 1996): 
Cook \& Mosley, Modelling acid solute fluxes to the water column in the Lower Lakes

$$
D_{m}=D_{s}+D_{b}+D_{i}+D_{w c}
$$

where $D_{s}$ is the molecular diffusion $\left(D_{s}=\tau D_{0}, \tau\right.$ is the tortuosity and $D_{0}$ is the molecular diffusion in water, $D_{b}$ due to particle mixing, $D_{i}$ is irrigation by benthic organisms and $D_{w c}$ is due to wave action and current mixing. The dispersion due to benthic organisms can have a large effect on $D_{m}$ (Van Rees et al. 1996) . However, in Lower Lakes, a consequence of the low water levels is that much of the benthic fauna died (Baring et al. 2008).

Modelling of the transport of solutes from the Lower Lake sediments to the water column was performed using eqn (4) to determine the sensitivity of the results to the parameter values, especially the dispersion and Darcy velocity. Modelling of fluxes for a number of sites where mesocosm studies (Hicks et al. 2009) were also carried out and the results compared to measured values of the flux of acidity from the sediments to the water column.

\section{METHODS}

The solute species that are of interest in the Lower Lake sediments are $\mathrm{H}^{+}, \mathrm{Fe}^{2+}$, and $\mathrm{Al}^{3+}$ and to a smaller extent $\mathrm{Mn}^{2+}$. The $D_{0}$ values for the first three solutes is given in Table 2. The model was tested for its sensitivity to changes in the initial concentration, the dispersion, the Darcy velocity and the depth of the acidity. In these sensitivity analyses, the concentration $c_{2}=0$. The range and base values for the parameters are given in table 2.

The initial conditions were taken from published data by Fitzpatrick et al. (2011) and Hicks et al. (2009). The modelled fluxes were then compared to those measured by Hicks et al. (2009) in their mesocosm studies.

The model was written in Matlab and the domain used was generally $<$ $4 \mathrm{~m}$ depth and $<200$ days in duration.

Some runs with the duration extended to 1000 days were performed
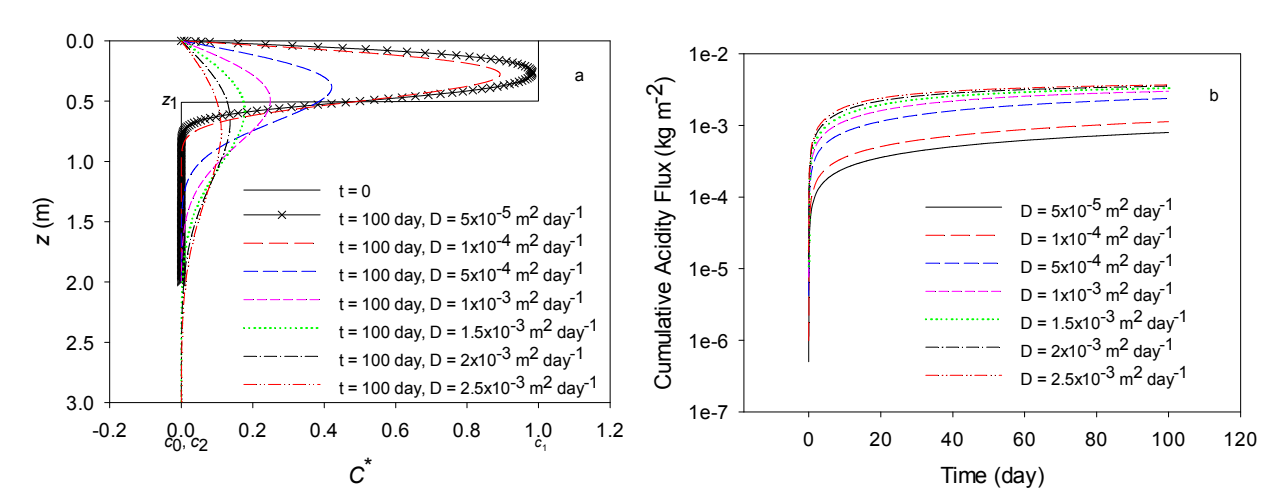

Figure 2. Modelled a) relative concentration $\left(C^{*}=c / c_{1}\right)$ profiles at $t=100$ day and b) cumulative flux to the water column with time for a range of different dispersivities $(D)$ for $q=0, c_{1}=10 \times 10^{-3} \mathrm{~kg} \mathrm{~m}^{-3}$ and $z_{1}=0.5 \mathrm{~m}$.

and more details, including the code, can be found Cook and Mosley (2012).

\section{RESULTS AND DISCUSSION}

\subsection{Sensitivity Analysis}

When diffusion is the only mechanism for acid flux $(q=0)$, increasing the dispersion resulted in spreading out of the acidity with the peak moving further into the
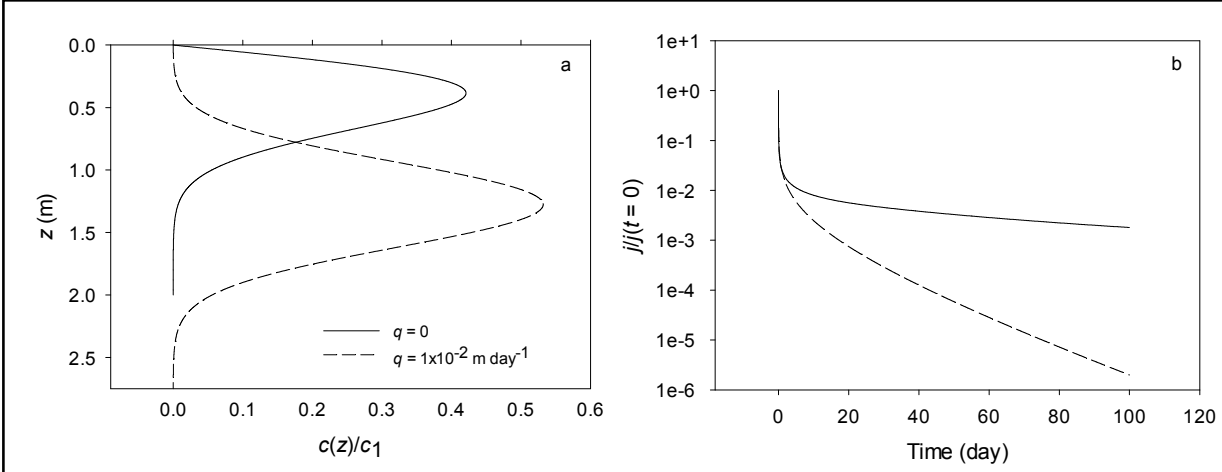

Figure 3. Modelled a) relative concentration profiles and $b)$ relative acidity fluxes $(j / j(t$ $=0)$ ) out of the sediment with time when the value of $c_{1}$ varied. The other parameter values are the base values given in Table 2 . 
sediment (Figure 3a) and the cumulative flux after 100 days increasing with increasing dispersion (Figure $3 \mathrm{~b})$. This is due to a much larger initial flux of acidity with the higher dispersivity. This would suggest that if benthic organisms were present and increased the dispersivity, an initial large flux of acidity could occur. However, the initial inundation is likely to result in a Darcy velocity (advection) into the sediment. This will shift the acidity peak further into the sediments and result in more rapid decrease in the acidity flux with time, and hence cumulative acidity flux (Cook and Mosley, 2012, Figure 21).

Increasing the initial concentration results in an increased store of acidity in the sediment profile results in an increase in the concentration in the sediment profile after 100 days of acidity transport to the water column and an increase in the flux with increase in concentration. However, the profiles are self-similar and scaling the concentration by $c_{1}$ and the flux by the flux at $t=0$ results in a single relationship. The effect of advection $(q>0)$ is that the concentration curve is pushed down the sediment profile (Figure $3 \mathrm{a})$, resulting in a decrease in the relative flux (Figure 3b) and actual flux (Cook and Mosley, 2012).

The

sensitivity of

the acidity

flux from the

sediments to

$z_{1}$ is shown

to increase

as $z_{1}$

increases

(figure $4 \mathrm{a}$ ),

but once $z_{1}$ is

$>0.75 \mathrm{~m}$

when $q=0$

and $>0.5 \mathrm{~m}$

when $q=$

$1 \times 10^{-3} \mathrm{~m}$
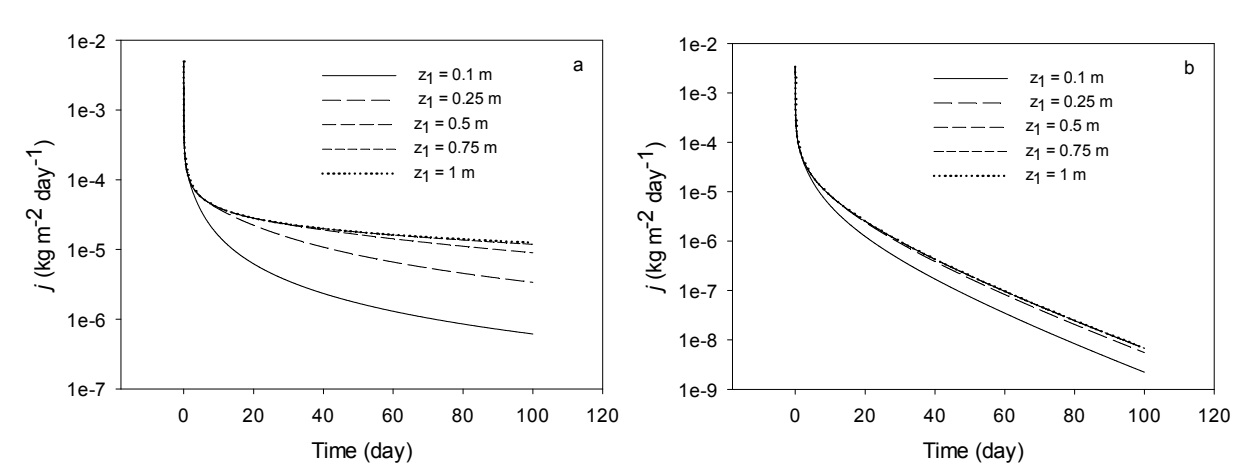

Figure 4. Modelled a) acidity flux $(j)$ with $q=0$ and b) acidity fluxes with $q=1 \times 10^{-2} \mathrm{~m}$ day $^{-1}$ for various values of $z_{1}$. The other parameter values are the base values given in Table 2 .

day $^{-1}$ (figure $4 \mathrm{~b}$ ), the flux as a function of time hardly changes with increasing $z_{1}$. This implies that the depth of oxidation of the sediments beyond a certain depth, dependent on the Darcy velocity, is unlikely to increase the flux of acidity to the water column but may extend the duration of this flux. However, no chemical reactions are included in this analysis, and at longer times reactions such as sulfate reduction are likely to have removed some acidity from the sediments. Investigations are underway of such reactions.

The effect of variation in the Darcy velocity (q) in the range likely to occur in the Lower Lakes was assessed.

Advection out of the sediments and into the water column will arise if the groundwater head in the
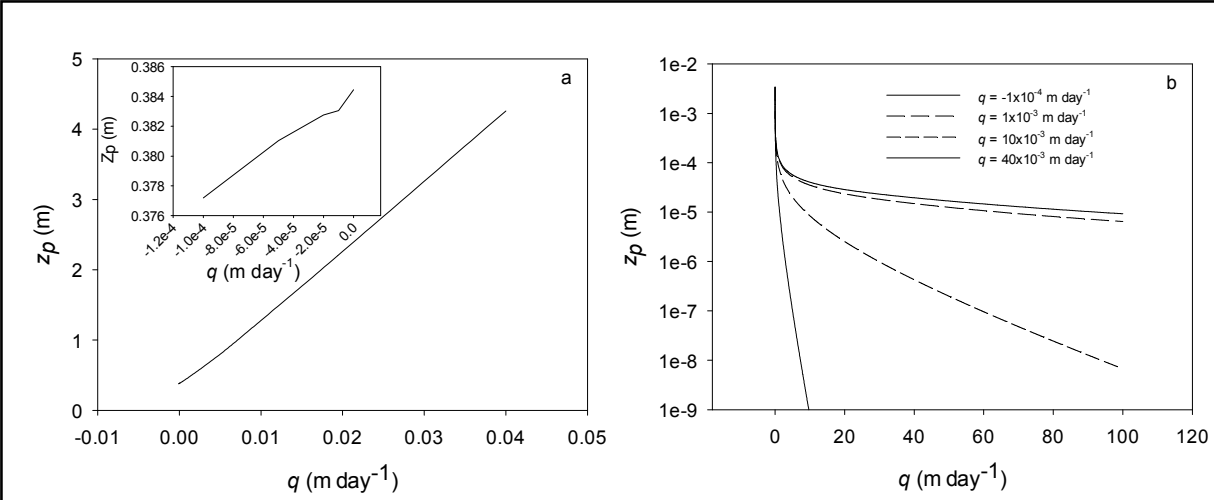

Figure 5. Modelled a) depth at which the peak concentration occurs $\left(z_{p}\right)$ with $q$, the insert shows values of $q<0$ in more detail and b) acidity fluxes with time for selected values of $q$. The other parameter values are the base values given in Table 2 . surrounding

landscape is higher than the Lake water column height. This gives likely values of $q$ ranging from $-1 \times 10^{-4} \mathrm{~m}$ day $^{-1}$ to 0 (Hipsey et al. 2010). During rewetting of the sediments, infiltration of water into them will occur, and using values from Hicks et al. (2009) and Cook et al. (2011) we used a range of $q$ from 0 to $40 \times 10^{-3} \mathrm{~m}$ day $^{-1}$. The results show that the depth of the peak of concentration after 100 days increases with increasing $q$ in an almost linear manner (Figure 5a). This moving of the solute deeper into the sediment with time has a dramatic effect on the acidity flux from the sediments, with the flux decreasing rapidly when $q=40 \times 10^{-3} \mathrm{~m}$ day $^{-1}$ (Figure 5b). This suggests that in sandier sediments with high infiltration rates, the acidity flux would be expected to decrease more quickly with time following inundation. 


\subsection{Comparison with Measurements}

Hicks et al. (2009) performed a number of studies of acidity flux from sediments into the water column at two sites, Boggy Creek and Point Sturt using both freshwater and salt water in these studies. These studies were continued for approximately 100 days (Table 1). They estimated acidity fluxes in the first few days and also in the remaining period as average fluxes for these periods of time. We estimated average fluxes for the same time periods from our modelling and compared the results (Table 1). In this modelling we took the dispersivity as $D_{0}$. This means that we are assuming that the processes that will enhance the dispersion are similar to the effect of including tortuosity in estimating the dispersion. A similar approach has

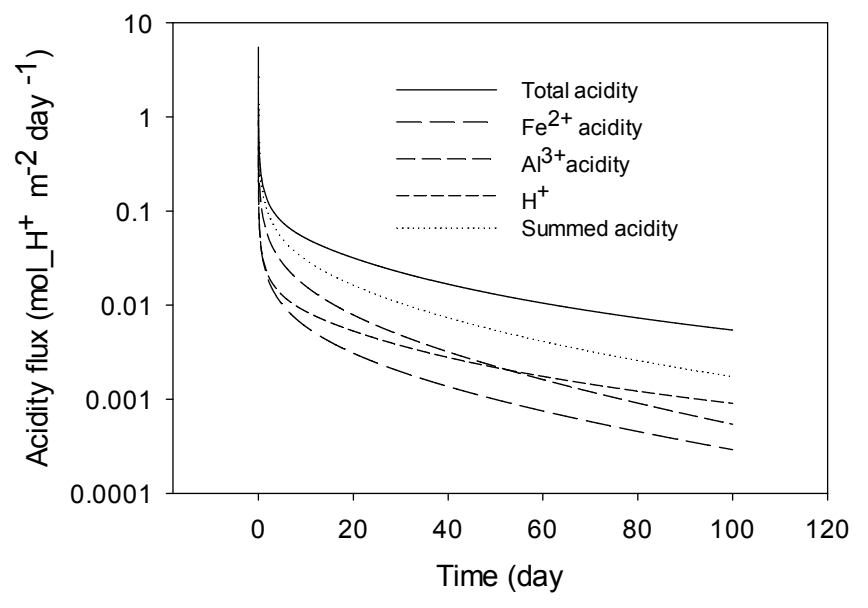

Figure 6. Modelled acidity flux for Boggy Creek freshwater mesocosm for the total acidity (assuming all acidic ions are $\mathrm{H}+$ ), the acidity due to $\mathrm{Fe}^{2+}, \mathrm{Al}^{3+}$ and $\mathrm{H}^{+}$and the sum of these

been taken by Di Toro (2000) in much of his and co-workers modelling of sediment solute fluxes. We modelled both the individual components of the acidity $\left(\mathrm{H}^{+}, \mathrm{Fe}^{2+}, \mathrm{Al}^{3+}\right)$ and summed these to give the summed acidity flux as well as converting these to their $\mathrm{H}^{+}$equivalent acidity and modelling as total acidity. The summed acidity flux was $<$ the total acidity flux (Figure 6) due to the lower values of $D_{0}$ for $\mathrm{Fe}^{2+}$ and $\mathrm{Al}^{3+}$ compared to $\mathrm{H}^{+}$(Table 2). The model overestimates the acidity flux initially except for the Point Sturt freshwater site. This overestimation could be due to the dispersivity being overestimated by $D_{0}$. However, given that no fitting was done to get $D_{0}$ the results are close to the measured values.

Ignoring advection (infiltration) results in modelled average fluxes $>$ measured average fluxes for time $>7$ days for the Boggy Creek site. The trend in both the measured and modelled acidity fluxes between freshwater and salt water is similar (Table 1).

At the Point Sturt site, the alkalinity of the water was measured to increase with time, resulting in a positive acidity flux. The simple model used here cannot produce the chemistry that occurs in the sediments that would have led to this flux of alkalinity to the water column, but we do estimate very low acidity fluxes due to a higher value of advection $q$ from Hicks et al. (2009) for this site. The model estimates much larger acidity fluxes in the first 5 days for the salt water site than does the measurements. This is in part due to using a constant value of $c_{1}$ with a fixed depth, where as the measured values (Figure 7) show an increasing

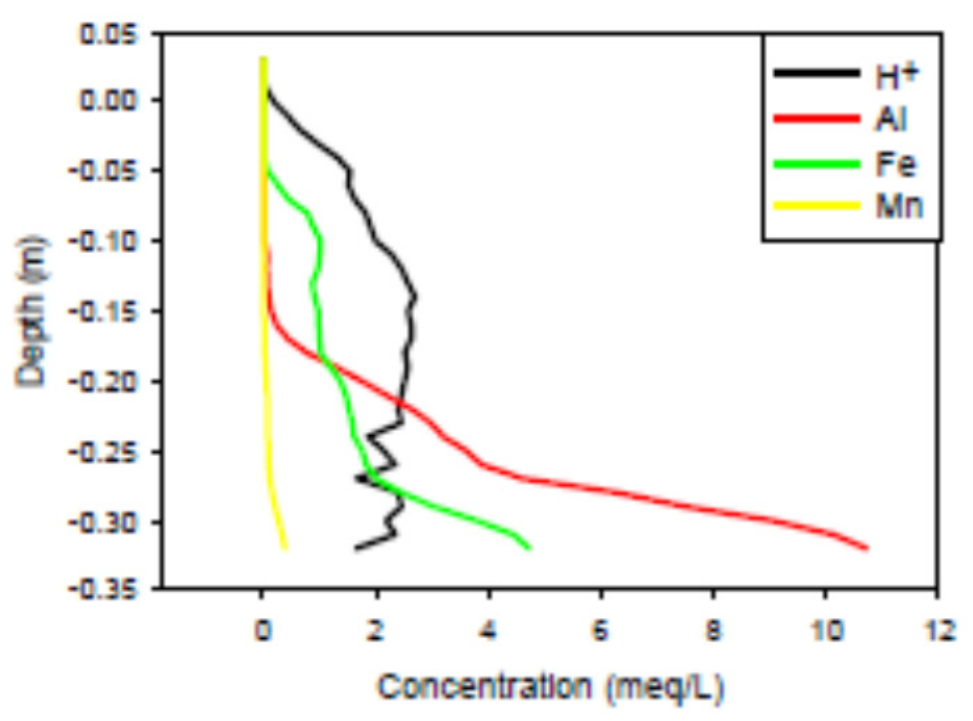

Figure 7. Concentration of $\mathrm{H}+, \mathrm{Fe}, \mathrm{Al}$ and $\mathrm{Mn}$ with depth at Point Sturt salt water site from Hicks et al. (2009. Figure 31). 
concentration with depth. Different values of $c_{1}, c_{2}$ and $z_{1}$ were tried, but this did not reduce the modelled initial acidity flux greatly due to the amount of $\mathrm{H}^{+}$near to the sediment surface (Figure 7).

\subsection{Long-term Modelling and General Discussion}

The temporal extent of the modelling presented was for only 100 days, but once inundation occurs, this process of acidicty flux to the water column could continue for much longer. Modelling for a period of 1000 days was performed. This modelling considered a worst-case scenario, with the highest acidity profiles measured by Hicks et al. (2009) at each site and $q=0$. The results indicated that the at the Boggy Creek site significant acidity could still be coming out of the sediments after 1000 days (Figure 8a), but at the Point Sturt site, the acidity flux is low especially for the salt water site.

During the drought, allowing salt water to enter the lakes to prevent drying out and to neutralize acidity was considered. This was not necessary due to breaking of the drought in 2010. However, Webster et al. (2008) suggested that this may not be a good idea as it could enhance transport of acidity from the sediments to the lake water. Both the measurements by Hicks et al. (2009) and the modelling results presented here and in Cook and Mosley (2012) show enhanced acidity transport in the first few days after inundation.

The reason for this modelling was to consider the likely effects of inundation on the alkalinity of the lake water. The reaction of the acidity with the lake water was discussed in Cook and Mosley (2012). These results
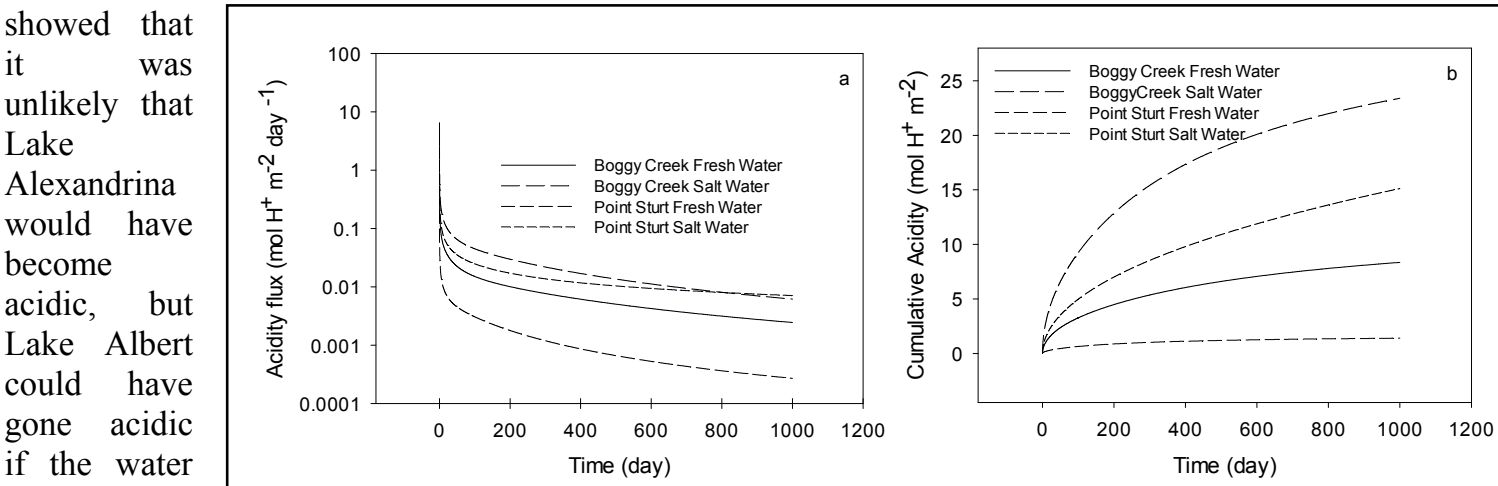

level had not been maintained.

Figure 8. Long term modelling of worst case scenario at each of the four sites of Hicks et al. (2009) for a) flux of acidity and b) cumulative acidity.

\section{CONCLUSIONS}

An analytical solution for solute transport in porous media was shown to successfully model acidity transport from lake sediment upon inundation. The sensitivity analysis showed that the flux of acidity was very sensitive to the Darcy flux, initial concentration and dispersivity, but less so to how deep the acidity extended in the sediment profile.

Comparisons of modelled results with measurements made in mesocosms were similar. These results show that this model will be of use in understanding the effect of management options for the Lakes and possible long term trends in the lake water quality. They can complement the more complicated models such as Hipsey et al. (2010).

\section{REFERENCES}

Baring R., Dittmann, S., Dutton, A., Gannon R., Cummings C., Humphries J., Hunt T. (2009). Macrobenthic survey 2008: Murray Mouth, Coorong and Lower Lakes Ramsar site. Report for the South Australian Murray Darling Basin Natural Resource Management Board; Adelaide.

Cook, F.J., McLachlan, G., Leyden, E., and Mosley. L. (2011). Physical properties of soils/sediments of Lower Murray Lakes and modelling of acid fluxes. CSIRO: Water for a Healthy Country National Research Flagship. 60 pp. http://www.clw.csiro.au/publications/waterforahealthycountry/2011/wfhc-LowerMurrayacid-fluxes.pdf

Cook, F.J., and Mosley, L., (2012). Modelling of acidic solute fluxes from sediments to the water column in the Lower Lakes of South Australia. Freeman Cook and Associates, Report, 66p. 
Di Toro, D.M. (2000). Sediment Flux Modelling. Wiley, New York, 624p.

Fitzpatrick, R.W., Grealish, G.J., Shand, P., and Creeper, N.L. (2011). Monitoring and assessment of reflooded acid sulfate soil materials in Currency Creek and Finniss River Region, South Australia. Prepared for the South Australia Department of Environment and Natural Resources (DENR), Adelaide. Client Report R-325-8-6. CSIRO: Sustainable Agriculture Research Flagship, 101 pp. Available at: http://www.clw.csiro.au/publications/science/2011/SAF-monitoring-ASS-Currency-Creek.pdf

Fitzpatrick, R.W., Shand, P., Marvanek, S., Merry, R.H., Thomas. M., Simpson, S.L., Raven, M.D., McClure, S. (2008). Acid sulfate soils in subaqueous, waterlogged and drained soil environments in Lake Albert, Lake Alexandrina and River Murray below Blanchetown (Lock 1): properties, distribution, genesis, risks and management. Prepared for Department for Environment and Heritage, SA. CSIRO Land and Water Science Report 46/08. CSIRO, Adelaide, 167. pp. Available at: http://www.clw.csiro.au/publications/science/2008/sr46-08.pdf.

Hicks, W.S., Creeper, N., Hutson, J., Fitzpatrick, R.W., Grocke, S., and Shand, P. (2009). The potential for contaminant mobilisation following acid sulfate soil rewetting: field experiment. Prepared by the Commonwealth Scientific and Industrial Research Organisation (CSIRO) Land and Water for the SA Department of Environment and Natural Resources, Adelaide. Available at: http://www.environment.sa.gov.au/files/b6b9ad2e-f460-460f-b36c-9ebb010f396f/cllmm-genacidsulfatesoils-report3.pdf.

Hipsey, M.R., Bursch, B.D., Colleti, J., and Salmon, S.U. (2010). Lower lakes hydrogeochemical model development and assessment of acidification risks. Prepared by University of Western Australia for SA Water.

Marion, A., Zaramella, M., and Packman, A.I. (2003). Parameter estimation of the transient storage model for stream-subsurface exchange. Journal of Environmental Engineering-ASCE, 129(5): 456-463.

Meysman, F.J.R., Galaktionov, O.S., Cook, P.L.M., Janssen. F., Huettel, M., and Middleburg, J.J. (2007). Quantifying biologically and physically induced flow and tracer dynamics in permeable sediments. Biogeosciences, 4(4): 627-646.

Mosley, L., Barnett, E., Leyden, E., Fradley, K., Lacopetta, J., Jolley, A-M., Mettam, P., Natt, A., Palmer, D., Scott, P., Spencer, J., Stone, D., and Zammit, B. (2013). Water quality in the lower lakes during a hydrological drought. Environment Protection Authority, South Australia http://www.epa.sa.gov.au/xstd_files/Water/Report/lower_lakes_WQ.pdf.

van Genuchten M.Th., and Alves, W.J. (1982). Analytical solutions of the one-dimensional convectivedispersion solute transport equation. U.S. Department of Agriculture, Technical Bulletin 1661, 151p.

van Rees, K.C.J., Reddy, K.R., and Rao, P.S.C. (1996). Influence of benthic organisms on solute transport in lake sediments. Hydrobiologia, 317(1): 31-40.

Webster, I.T., Cook, F.J., and Hicks, W.S. (2008). Appendix C. Review of Hipsey and Salmon: Numerical Assessment of Acid-Sulfate Soil Impact on the River Murray Lower Lakes During Water Level Decline. In Peer Review of Acidification Thresholds for Lake Alexandrina and Lake Albert, Aquaterra (2008), 38-50. 